\title{
Kindlin-2 expression in adult tissues correlates with their embryonic origins
}

\author{
ZHAN Jun ${ }^{1,2,3}$, YANG Mei ${ }^{1,2,3}$, CHI XiaoChun ${ }^{1,2,3}$, ZHANG Jing ${ }^{1,2,3}$, PEI XueLian ${ }^{1,2,3}$, \\ REN CaiXia ${ }^{1,2,3}$, GUO YongQing ${ }^{4}$, LIU Wei ${ }^{5}$ \& ZHANG HongQuan ${ }^{1,2,3^{*}}$ \\ ${ }^{1}$ Key Laboratory of Carcinogenesis and Translational Research, Ministry of Education, Peking University Health Science Center, Beijing \\ 100191, China; \\ ${ }^{2}$ State Key Laboratory of Natural and Biomimetic Drugs, Peking University Health Science Center, Beijing 100191, China: \\ ${ }^{3}$ Laboratory of Molecular Cell Biology and Tumor Biology, Department of Anatomy, Histology and Embryology, Beijing 100191, China; \\ ${ }^{4}$ Department of Thoracic Surgery, Sino-Japan Friendship Hospital, Beijing 100100, China; \\ ${ }^{5}$ Department of Immunology, Third Military Medical University, Chongqing 400038, China
}

Received February 28, 2014; accepted May 6, 2014; published online June 6, 2014

\begin{abstract}
Kindlin-2 functions in the maintenance of homeostasis and in human diseases. This study investigated the interrelationship between Kindlin-2 expression in tissues and the corresponding germ layers from which these tissues originated. Kindlin- 2 expression was examined in normal adult human organs and human cancer tissues by immunohistochemical analyses. Analysis of Kindlin-2 mRNA levels in adult human organs in the Oncomine dataset revealed Kindlin-2 is highly expressed in mesoderm-derived organs. However, Kindlin-2 was negative or weakly expressed in endoderm/ectoderm-derived organs. Interestingly, the abnormal expression of Kindlin-2 was observed in a variety of human cancers. In agreement with its expression profile in humans, Kindlin-2 was also highly expressed in mesoderm-derived organs in mouse embryos with the exception of strong Kindlin-2 expression in ectoderm-derived spinal cord and ganglia, tissues that are highly mobile during embryonic development. Importantly, we demonstrated the expression level of Kindlin-2 in adult organs correlated with their embryonic dermal origins and deregulation of Kindlin-2 in tissues is associated with tumor progression. This finding will help us understand the dual role of Kindlin-2 in the regulation of tumor progression and embryonic development.
\end{abstract}

Kindlin-2, germinal layers, migration, embryo

Citation: Zhan J, Yang M, Chi XC, Zhang J, Pei XL, Ren CX, Guo YQ, Liu W, Zhang HQ. Kindlin-2 expression in adult tissues correlates with their embryonic origins. Sci China Life Sci, 2014, 57: 690-697, doi: 10.1007/s11427-014-4676-4

Kindlin-2 (encoded by the FERMT2 gene) is an important molecule that binds to the integrin $\beta$ cytoplasmic tail via a C-terminal FERM-like domain to promote integrin activation [1-3]. The integrity of Kindlin-2 subdomains is a prerequisite for supporting integrin recognition and subsequent integrin activation [4].

In the past decade Kindlin-2 was shown to be involved in tumor progression, promoting the migration of non-smallcell lung cancer cells [5], and the invasion of breast cancer

*Corresponding author (email: Hongquan.Zhang@bjmu.edu.cn) cells [6]. Kindlin-2 is expressed in high-grade invasive bladder cancers [7]. Recently, it was reported that Kindlin-2 promotes the invasion of gastric cancer cells by enhancing cell proliferation and adhesion by phosphorylation of integrin $\beta 1$ and $\beta 3$ [8]. Kindlin-2 has potential as a prognostic marker for tumor progression and outcome prediction of gastric cancer patients [9] and pancreatic ductal adenocarcinoma [10]. In addition, Kindlin-2 is a new regulator of Wnt signaling and promotes cancer progression by an integrin-independent pathway [11]. Targeting Kindlin-2 can suppress tumor cell invasiveness and modulate cytoskeletal 
and adhesive machinery in esophageal squamous carcinoma cells [12]. Interestingly, all the cancers mentioned above are derived from endodermal/ectodermal organs.

Kindlin-2 is widely expressed in normal human organs. Genetic deficiency of Kindlin-2 is embryo lethal in mice [13]. The tissue distribution of Kindlin-2 genes analyzed by multiple tissue Northern blots, RT-PCR and in situ hybridization in mice demonstrated it is preferentially expressed in striated and smooth muscle cells [14]. However, the localization of Kindlin-2 protein in embryos in situ is unknown. Kindlin-2 and Perlecan participate in the integrin attachment complex required for proper maintenance of adult muscle [15]. Kindlin-2 is also essential for myocyte elongation. Myogenesis [16] is an essential component of intercalated discs and is required for vertebrate cardiac structure and function [17]. Kindlin-2 also correlates with angiogenesis [13]. Furthermore, Kindlin-2 controls the dynamics of $\beta 1$ integrin-containing fibrillar adhesion and thereby regulates fibronectin deposition and osteoblast mineralization [18]. Interestingly, the organs where Kindlin-2 plays important functional roles are derived from mesoderm including striated and smooth muscle, vessels, and bone. However, the meaning of the embryonic origin of these organs with Kindlin-2 expression remains unknown.

In physiological conditions of wound closure and tissue repair, strong upregulation of Kindlin-2 in contractile myofibroblasts was observed during the middle stages of wound healing in human skin [19]. By activating Ras and downstream ERK1/2 and Akt signaling pathways, Kindlin-2 plays an important role in regulating renal tubular epithelium-to-mesenchymal transition (EMT) [20,21]. Importantly, Kindlin-2 interacts physically with T $\beta R I$ and Smad3, promoting the activation of transforming growth factor (TGF)- $\beta /$ Smad signaling and contributing to the pathogenesis of tubulointerstitial fibrosis. This finding revealed that Kindlin-2 could be a potential therapeutic target for the treatment of fibrotic kidney diseases [22]. Therefore, Kindlin-2 not only promotes migration, invasion and progression of tumors but also correlats with fibrosis and EMT in non-tumor tissues. We hypothesize that Kindlin-2 may play a key role in embryonic dermal development.

During embryo development, the bilaminar germ disk differentiates further to a trilaminar embryo, where cells that flow over the primitive streak between the two already existing germinal layers form a third embryonic germinal layer (mesoblast/derm) [23,24]. This phenomenon is also termed EMT $[25,26]$. Notochord induces differentiation of the neuroblast. The median part of the epiblast thickens and forms a groove, out of which the central nervous system arises [27]. From the edges of the neural groove the neural crest cells are released, and the largest part of the peripheral nervous system including the spinal ganglia are generated through EMT [27]. This study investigated which germinal layers show Kindlin-2 expression and the distribution of Kindlin-2 expression during embryonic development.

\section{Materials and methods}

\subsection{Normal and tumor tissues}

We obtained samples of cancer tissues and normal control tissues from patients who underwent tumor resection at $\mathrm{Si}$ no-Japan Friendship Hospital between July 2010 and September 2013.

\subsection{Animal experiments}

Ten-week-old ICR pregnant female mice were bred in a room with $12 \mathrm{~h} / 12 \mathrm{~h}$ light-dark cycles and given food and water ad libitum. We acquired embryos of mice 16.5 days after copulation and whole embryos were formalin-fixed and paraffin-embedded.

\subsection{Immunohistochemistry (IHC)}

All slides were formalin-fixed and paraffin-embedded. Deparaffinization and hydration were performed followed by removal of endogenous peroxidase activity using $0.3 \%$ hydrogen peroxide for $30 \mathrm{~min}$. Antigen retrieval was performed by microwaving the sample in $10 \mathrm{mmol} \mathrm{L}^{-1}$ sodium citrate buffer ( $\mathrm{pH}$ 6.0) for $20 \mathrm{~min}$. Anti-Kindlin-2 mouse monoclonal antibody (1:1000 dilution; Millipore, Billerica, MA, USA) $2 \mu \mathrm{g} \mathrm{mL}^{-1}$ was used for experiments. The primary antibody was incubated at $4^{\circ} \mathrm{C}$ overnight. Then, PV9000 2-step plus Poly-HRP Anti-mouse/rabbit IgG Detection System (Zhong Shan Jin Qiao, China) was used. The streptavidin-biotin-peroxidase method was used for detection and diaminobenzidine was used as a substrate (ChemMate Detection Kit, Dako, Denmark). Hematoxylin was used for counterstaining. Negative controls were performed by omitting the primary antibody.

\section{Results}

\subsection{Kindlin-2 is highly expressed in mesoderm-derived organs of human adults}

Kindlin-2 was expressed in tongue skeletal muscle (Figure 1A) with clear transverse striation (Figure 1A, black arrow). Kindlin-2 was found highly expressed in cardiac muscles (Figure 1B), especially at the position of intercalated disc (Figure 1B, black arrow). The capillaries inter-cardiac muscle fibers expressed high level of Kindlin-2 (Figure 1B, black arrow-head). Stroma cells (Figure 1C, black arrow) of the testis, epithelial of the prostate gland (Figure 1D) and kidney tubules (Figure 1E) all displayed highly Kindlin-2 expression. The distal convoluted tubules (Figure 1E, black arrow) expressed higher levels of Kindlin-2 than the proximal convoluted tubules (Figure 1E, black arrow-head). Obvious positive Kindlin-2 staining was detected in blood vessels (Figure 1F). Medium- and small-sized artery (Figure $1 \mathrm{~F}$, black and red arrows) and medium-and small-sized vein 

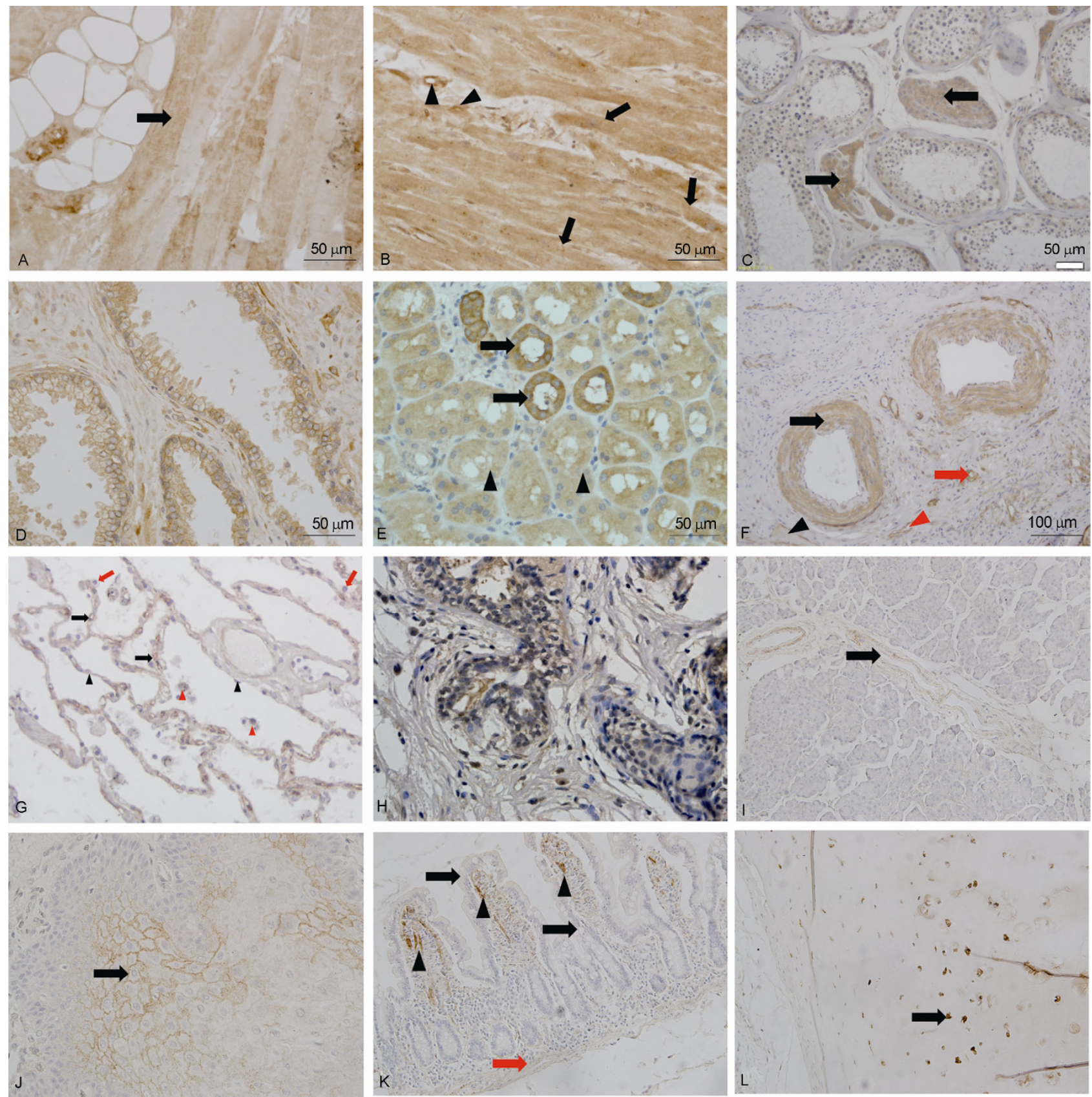

Figure 1 Kindlin-2 expression at various levels in human adult normal organs. A, Skeletal muscles prepared from tongue. Black arrow: transverse striation of skeletal muscles. B, Cardiac muscles. Black arrow: intercalated disc; black arrow-head: the capillaries inter-cardiac muscle fibers. C, Testis. Black arrow: stroma cells. D, Prostate. E, Kidney tubules. Black arrow: the distal convoluted tubules; black arrow-head: proximal convoluted tubules. F, Blood vessels. Black arrow: medium-sized artery; black arrow-head: medium-sized vein; red arrow: small-sized artery; red arrow-head: small-sized vein. G, Lung tissue. Black arrow: capillaries; black arrow-head: type I alveolar epithelial cells; red arrow: type II alveolar epithelial cells; red arrow-head: macrophages. H, Mammary gland. I, Pancreas tissue. Black arrow: mesenchyme of pancreases. J, Tonsil. Black arrow: middle layer cells of stratified squamous epithelium. K, Intestinal duct. Black arrow: simple columnar epithelium cells; black arrow-head: connective tissue in lamina propria; red arrow: smooth muscle. L, Hyaline.

(Figure 1F, black and red arrow-heads) all exhibited high levels of Kindlin-2 staining.

\subsection{Kindlin-2 is not expressed or weakly expressed in endoderm- and ectoderm-derived organs of human adults}

In the lung Kindlin-2 was mainly detected in capillaries
(Figure 1G, black arrow) of lung stroma, but type I and II alveolar epithelial cells (Figure 1G, black arrow-head and red arrow) and macrophages (Figure 1G, red arrow-head) had no Kindlin-2 expression. Kindlin-2 was weakly expressed in the normal lobules of the mammary gland (Figure $1 \mathrm{H})$. No Kindlin-2 staining was observed in the parenchyma of normal pancreas tissues (Figure 1I). However, 
Kindlin-2 was present in the mesenchyme (Figure 1I, black arrow). In tonsils, Kindlin-2 expression was localized in the middle layer cells of cell-cell contact in stratified squamous epithelium (Figure 1J, black arrow), whereas other parts of the tonsil were negative (Figure 1J). Gastric-intestinal ducts displayed a similar pattern of Kindlin-2 expression (Figure $1 \mathrm{~K}$ ). Simple columnar epithelium cells (Figure $1 \mathrm{~K}$, black arrow), were negative for Kindlin-2, whereas connective tissues in the lamina propria were positive (Figure 1K, black arrow-head). The smooth muscle layer (Figure 1K, red arrow) and bone cells of hyaline (Figure 1L, black arrow) were Kindlin-2 positive.

\subsection{Mesoderm-derived organs express higher Kindlin-2} mRNA compared with endoderm- and ectoderm-derived organs of human adults

Kindlin-2 expression in the Shyamsundar Normal database of Oncomine was reanalyzed. We compared Kindlin-2 expression levels between mesoderm originating organs (heart, bladder, prostate gland, ovary, seminal vesicle, fallopian tube, kidney, and testis) and endoderm/ectoderm originating organs (esophagus, lung, breast, liver, pancreas, spleen, stomach, thymus gland, thyroid gland, and tonsil). Results indicated that the mesoderm group (red frame) had significantly higher Kindlin-2 expression than the endoderm/ ectoderm group (green frame) $(P<0.05)$ (Figure 2).

\subsection{Kindlin-2 is weakly expressed in cancers derived from the mesoderm}

Kidney clear cell carcinoma (Figure 3A, black arrow) displayed lower Kindlin-2 expression than normal kidney tissues (Figure 3A, black arrow-head) adjacent to the tumor. Likewise, prostate cancer tissues (Figure 3B, black arrow) exhibited lower Kindlin-2 expression compared with normal epithelia (Figure 3B, black arrow-head) adjacent to the tumor tissues.

\subsection{Kindlin-2 is highly expressed in tumor tissues de- rived from the endoderm and ectoderm}

Breast cancer (Figure 3C) expressed higher Kindlin-2 protein levels than normal breast lobules (Figure 1H). In pancreatic cancer (Figure 3D), Kindlin-2 expression was higher compared with normal pancreas alveolus and ducts (Figure 1I). Higher expression of Kindlin-2 was detected in lung adenocarcinoma (Figure 3E) and lung large cell carcinoma (Figure $3 \mathrm{~F}$ ) compared with normal lung alveoli (Figure 1G).

\subsection{Kindlin-2 is highly expressed in mesoderm- and neural tube-derived organs in the mouse embryo}

In mouse embryonic pancreas (Figure 4B, black arrow; Figure 4D), Kindlin-2 was not expressed in pancreas alveoli (Figure 4D, black arrow) or epithelia of ducts (Figure 4D, black arrow-head), However, Kindlin-2 was present in the mesenchyme (Figure 4D, red arrow) and smooth muscles of the duct (Figure 4D, red arrow-head). In embryonic intestines (Figure 4B, black arrow-head; Figure 4F), epithelial tissues (Figure 4F, black arrow) were Kindlin-2 negative. Loose connective tissues (Figure 4F, black arrow-head) and smooth muscle tissues (Figure 4F, red arrow) exhibited positive expression of Kindlin-2. In embryonic lungs the parenchyma (Figure $4 \mathrm{H}$, black arrow) was negative However, the mesenchyme (Figure 4H, black arrow-head) was strongly positive. In the middle of the embryonic body (Figure 4J), Kindlin-2 was strongly expressed in the skeletal muscle (Figure 4J, black arrow) and spinal cord (Figure 4J, black arrow-head), whereas the vertebra (Figure 4J, red arrow) were negative. Kindlin-2 was expressed in some areas of the mouth cavity (Figure 4L), and tongue skeletal muscle (Figure 4L, black arrow). However the stratified squamous epithelium (Figure 4L, black arrow-head) of the tongue and hyoid bone (Figure 4L, red arrow) was Kindlin-2 negative. Embryo skin (Figure 4N) and dermis (Figure 4N, black arrow) expressed high levels of Kindlin-2 and the epidermis

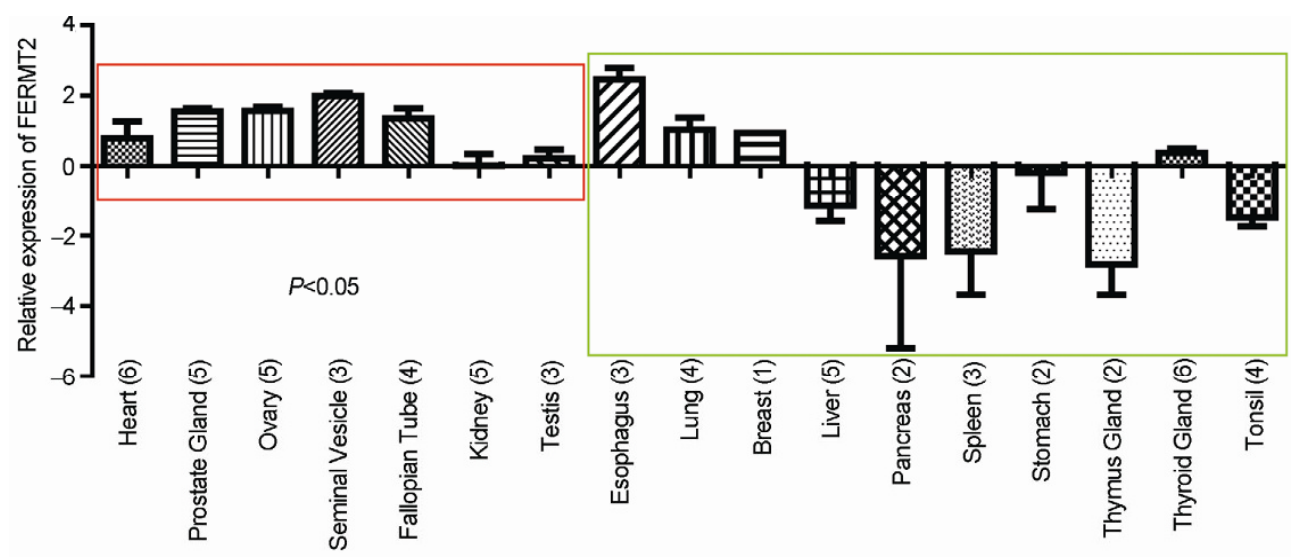

Figure 2 Mesoderm-derived organs express higher level of Kindlin-2 mRNA compared with endoderm and ectoderm-derived organs of adult. Mesoderm group (red frame) expressed significantly higher level of Kindlin-2 than endoderm/ectoderm group (green frame), $P<0.05$. 

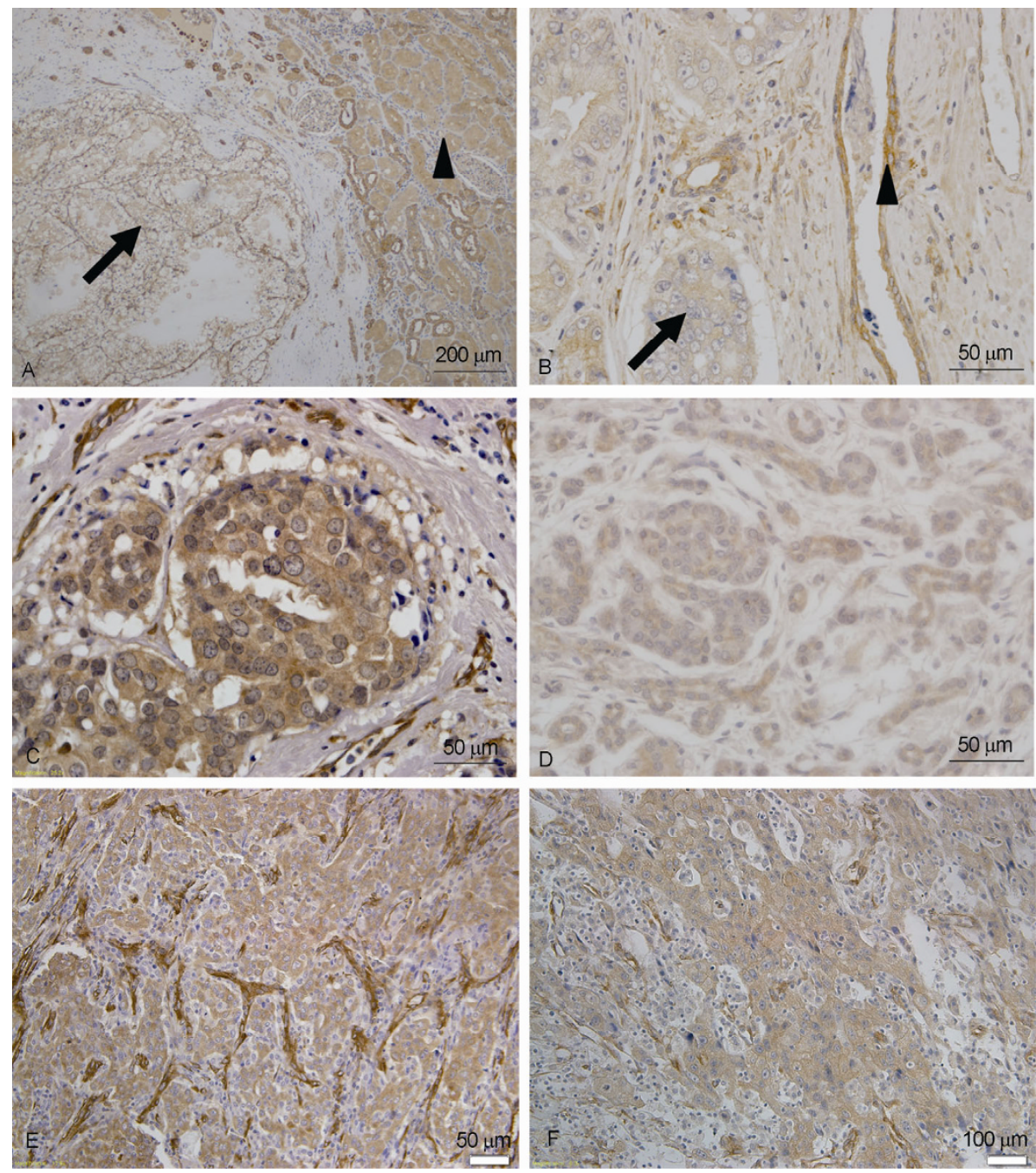

Figure 3 Kindlin-2 expression in human cancers. A, Kidney cancer. Black arrow: clear cell carcinoma; black arrow-head: relative normal kidney tissue adjacent to tumor. B, Prostate cancer. Black arrow: cancer tissue; black arrow-head: relative normal kidney tissue adjacent to tumor. C, Breast cancer. D, Pancreatic cancer. E, Lung adenocarcinoma. F, Lung large cell carcinoma.

(Figure 4N, black arrow-head) had weak expression. High Kindlin-2 levels were observed in the embryonic cardiac-vesicular system (Figure 4P) including the heart (Figure 4P, black arrow) and blood vessels (Figure 4P, black arrow-head). Spinal ganglia (Figure $4 \mathrm{R}$ and $\mathrm{T}$, black arrow) during the process of cell migration showed the highest Kindlin-2 expression.

\section{Discussion}

Combining the results of IHC from normal adult human organs (Figure 1), mouse embryos (Figure 4), the Oncomine dataset analysis (Figure 2), and other previously reported results indicates that Kindlin-2 is highly expressed in organs originating from the mesoderm, but is weak or negatively expressed in organs originating from the endoderm/ ectoderm. Furthermore, within a single organ Kindlin-2 is highly expressed in mesoderm-derived tissues but low or negatively expressed in endoderm/ectoderm- derived tissues. For example, mesenchymal tissues in the pancreas, smooth muscles in the intestine, and mesenchymal tissues of the lung are all derived from the mesoderm and displayed high levels of Kindlin-2 expression. However, the epithelia of these organs derived from endoderm do not show Kindlin-2 expression. These phenomena exist both in adults and embryos, suggesting that Kindlin-2 tissue expression is highly associated with their germ disk origins. The relationship of Kindlin-2 expression in various tissues and their embryonic origins are summarized in Table 1.

Kindlin-2 is upregulated in many cancer tissues including non-small-cell lung cancer [5], breast cancer [6], bladder cancer [7], and gastric cancer [8] to promote tumor invasion and metastasis. The current study observed Kindlin-2 expression was upregulated in pancreatic and large cell lung cancers. In contrast, Kindlin-2 was downregulated in kidney 

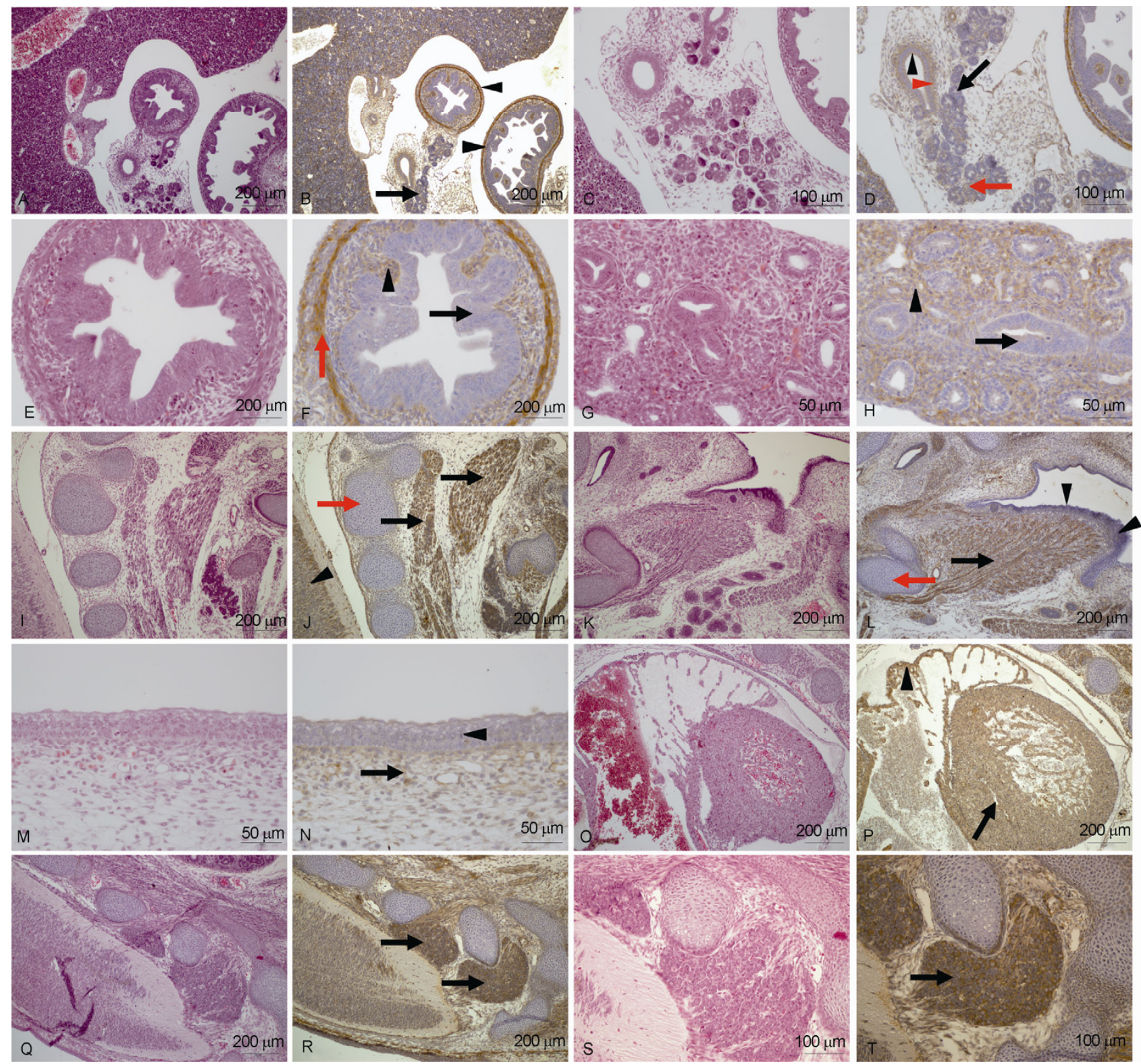

Figure 4 Kindlin-2 expression pattern in day 16.5 mouse embryo. A, C, E, G, I, K, M, O, Q, and S: H\&E staining of the day 16.5 mouse embryo. B, D, F, H, J, L, N, P, R, T: consecutive sections corresponding to their neighbor. B, Abdomen of embryo. Black arrow: pancreas; black arrow-head: intestine. D, Pancreas of embryo. Black arrow: pancreas alveoli; black arrow-head: epithelium of ducts; red arrow: mesenchyme of embryonic pancreas; red arrow-head: smooth muscle in the ducts. F, Intestines. Black arrow: embryonic intestines epithelial tissues; black arrow-head: loose connective tissue; red arrow: smooth muscles. H, Lung. Black arrow: the parenchyma of embryonic lung tissue; black arrow-head: the mesenchyme in lung. J, The middle of the embryonic body. Black arrow: skeletal muscle; black arrow-head: spinal cord; red arrow: vertebral column. L, The mouth cavity. Black arrow: tongue skeletal muscle; black arrow-head: stratified squamous epithelium of tongue; red arrow: hyoid bone. N, Skin of the embryo. Black arrow: dermis; black arrow-head: epidermis. P, Cardio-vesicular system in embryo. Black arrow: heart; black arrow-head: blood vessel. R and T, Spinal ganglia. Black arrow: spinal ganglia.

and prostate cancers compared with normal tissues. Interestingly, high Kindlin-2 expression inhibited tumor cell motility and invasion in SK-LMS-1 leiomyosarcoma cells that originate from the mesoderm [28]. Therefore, Kindlin-2 plays a dual role in cancers: by promoting tumor growth and invasion or inhibiting these effects. Thus, deregulation of Kindlin-2 is associated with tumor progression. It is of interest to understand why Kindlin-2 has a dual role during cancer progression. By analyzing Kindlin-2 expression pat- terns in adult human organs, mouse embryos and the Oncomine datasets, we identified a general rule that organs originating from the endoderm intrinsically expressed low levels of Kindlin-2, and when these organs become cancerous. Kindlin-2 expression is reversely upregulated. However organs originating from mesoderm intrinsically express high levels of Kindlin-2, and when these organs become cancerous. Kindlin-2 expression is downregulated. Following this rule, we predicted that Kindlin-2 expression would 
Table 1 Comparison of Kindlin-2 expression among organs derived from different embryo dermal layers ${ }^{\text {a) }}$

\begin{tabular}{|c|c|c|c|c|c|c|c|c|}
\hline $\begin{array}{l}\text { Trilaminar } \\
\text { germ disk }\end{array}$ & Diffe & erentiation & Differentiated organs & $\begin{array}{l}\text { Expression of } \\
\text { Kindlin- } 2 \text { in } \\
\text { adult } \\
\end{array}$ & $\begin{array}{c}\text { On- } \\
\text { comine }\end{array}$ & $\begin{array}{l}\text { Expression of } \\
\text { Kindlin- } 2 \text { in } \\
\text { embryo of mice } \\
\end{array}$ & $\begin{array}{l}\text { Cancer vs. } \\
\text { Normal }\end{array}$ & Other disease \\
\hline \multirow{4}{*}{ Ectoderm } & \multirow{4}{*}{$\begin{array}{c}\text { Neural tube } \\
\text { Neural } \\
\text { crest }\end{array}$} & \multirow{4}{*}{$\begin{array}{c}\text { Central nervous } \\
\text { system } \\
\text { Peripheral } \\
\text { nervous system }\end{array}$} & Brain and spine & & & $\mathrm{H}$ & & \\
\hline & & & $\begin{array}{l}\text { Peripheral nerves including } \\
\text { spinal ganglia }\end{array}$ & & & $\mathrm{H}$ & & \\
\hline & & & Epidermis & & & $\mathrm{L}$ & & \\
\hline & & & $\begin{array}{l}\text { Skin, Lining of mouth, Anus, } \\
\text { Nostrils, Sweat glands, Hair and } \\
\text { Nails }\end{array}$ & $*[19]$ & & & & \\
\hline \multirow{10}{*}{ Mesoderm } & \multirow{5}{*}{$\begin{array}{l}\text { Paraxial } \\
\text { mesoderm } \\
\text { (Somites) }\end{array}$} & \multirow{3}{*}{ Myotome } & Smooth muscle & $H^{*}[28]$ & & $\mathrm{H}$ & $\underline{\mathrm{L}}[28]$ & \multirow[b]{5}{*}{ Human skin tissue repair } \\
\hline & & & Cardiac muscle & $\mathrm{H}^{*}[17]$ & & $\mathrm{H}$ & & \\
\hline & & & Skeletal muscle & $\mathrm{H}^{*}[15,16]$ & & $\mathrm{H}$ & & \\
\hline & & Sclerotome & Cartilage & $\mathrm{H}^{*}$ & & & & \\
\hline & & Dermatome & Subcutaneous tissue of the skin & & $\mathrm{H}$ & $\mathrm{H}$ & & \\
\hline & \multirow[t]{2}{*}{$\begin{array}{l}\text { Intermedi- } \\
\text { ate meso- } \\
\text { derm }\end{array}$} & \multirow[t]{2}{*}{$\begin{array}{l}\text { Urogenital sys- } \\
\text { tem }\end{array}$} & $\begin{array}{l}\text { Kidneys, gonads, their associ- } \\
\text { ated ducts, and the adrenal } \\
\text { glands }\end{array}$ & $\mathrm{H}^{*}[22]$ & $\mathrm{H}$ & & $\mathrm{L}$ & $\begin{array}{l}\text { regulate renal tubular } \\
\text { EMT; tubulointerstitial } \\
\text { fibrosis;fibrotic kidney } \\
\text { diseases }\end{array}$ \\
\hline & & & Prostate & $\mathrm{H}$ & $\mathrm{H}$ & & $\mathrm{L}$ & \\
\hline & \multirow{3}{*}{$\begin{array}{l}\text { Lateral } \\
\text { plate mes- } \\
\text { oderm }\end{array}$} & \multirow{3}{*}{$\begin{array}{l}\text { Somatopleural } \\
\text { mesoderm and } \\
\text { splanchnopleu- } \\
\text { ral mesoderm }\end{array}$} & Heart & $\mathrm{H}$ & $\mathrm{H}$ & $\mathrm{H}$ & & \\
\hline & & & $\begin{array}{c}\text { Blood vessels } \\
\text { Blood cells of the circulatory } \\
\text { system }\end{array}$ & $\mathrm{H}^{*}[13]$ & & $\mathrm{H}$ & & \\
\hline & & & $\begin{array}{l}\text { The mesodermal component of } \\
\text { the limbs }\end{array}$ & & & $\mathrm{H}$ & & \\
\hline \multirow{9}{*}{ Endoderm } & \multirow{6}{*}{$\begin{array}{l}\text { Digestive } \\
\text { tube }\end{array}$} & & Tonsil & $\mathrm{L}$ & $\mathrm{L}$ & & & \\
\hline & & & Esophagus & & $\mathrm{H}$ & & $\underline{\mathrm{H}[12]}$ & \\
\hline & & & Gastric & & $\mathrm{L}$ & & $\underline{\mathrm{H}}[8,9]$ & \\
\hline & & & Liver & & $\mathrm{L}$ & & & \\
\hline & & & Small intestinal & $\mathrm{L}$ & & & & \\
\hline & & & Colon & $\mathrm{L}$ & & $\mathrm{L}$ & & \\
\hline & \multirow{2}{*}{\multicolumn{2}{|c|}{$\begin{array}{l}\text { Respiratory } \\
\text { tube }\end{array}$}} & Trachea & & & & & \\
\hline & & & Lung & $\mathrm{L}$ & $\mathrm{H}$ & $\mathrm{L}$ & $\mathrm{H} / \underline{\mathrm{H}}[5]$ & \\
\hline & Others & & Thymus & & $\mathrm{L}$ & & & \\
\hline
\end{tabular}

a) H, high expression of Kindlin-2; L, low expression of Kindlin-2 in organs. * Previously reported that Kindlin-2 has important roles in this organ. Underlined $\mathrm{H}$ and $\mathrm{L}$ indicate results from other studies.

be downregulated in ovary and fallopian tube cancers and upregulated in esophageal cancer. These predictions require further experimental confirmation.

The finding that Kindlin-2 was mainly expressed in the mesoderm during embryonic development indicated it might have an important role in the formation and differentiation of the mesoderm. A pivotal role for Kindlin-2 in mesodermal development was supported by the finding that Kindlin-2 deficiency led to failure of cardio-vascular formation in early embryogenesis [17].

In addition, it seems contradictory to dogma that Kindlin-2 expression was also highly expressed in spinal cord and spinal ganglia that originate from ectoderm. However, the process of neural tube formation is similar to mesodermal generation, involving EMT [29]. Therefore,
Kindlin-2 is expressed mainly in cells with a high capability for migration during embryonic development.

In summary, this study demonstrated that integrininteracting protein Kindlin-2, a key molecule in integrin activation, is highly expressed in mesoderm-derived organs in mouse embryos and has an important role in embryonic development. In adults, the tendency for Kindlin-2 high expression is maintained in organs originating from the mesoderm. Deregulated Kindlin-2 expression correlates with the development of human cancers. We conclude that Kindlin-2 tends to be highly expressed in cells and tissues with high migratory capacity both in embryos and in human cancers.

The authors declare that they do not have any conflict of interest. 
The Ethics Committee of Peking University Health Science Center approved the current study for mouse experiments (Permit Number: LA2011-73). The Ethics Committee of Sino-Japan Friendship Hospital approved the current study using lung cancer, breast cancer, pancreas cancer, adrenal cancer, prostate cancer, and relative normal tissues (Permit Number: ZRLW-7). The procedures for handling mice and human materials were in accordance with the ethical standards of the Helsinki Declaration of 1975 (as revised in 2008) concerning Human and Animal Rights, and they followed the policy concerning Informed Consent as shown at Springer.com.

This work was supported by the National Natural Science Foundation of China (81301802, 81230051, 30830048, 81321003, 31170711), Ministry of Science and Technology of China (2013CB910501, 2010CB912203, 2010CB529402), Program of Introducing Talents of Discipline to Universities of Ministry of Education, Beijing Natural Science Foundation (7120002), Peking University (BMU20120314, BMU20130364), and a Leading Academic Discipline Project of Beijing Education Bureau.

1 Kahner BN, Kato H, Banno A, Ginsberg MH, Shattil SJ, Ye F. Kindlins, integrin activation and the regulation of talin recruitment to alphaiibbeta3. PLoS ONE, 2012, 7: e34056

2 Perera HD, Ma YQ, Yang J, Hirbawi J, Plow EF, Qin J. Membrane binding of the N-terminal ubiquitin-like domain of kindlin-2 is crucial for its regulation of integrin activation. Structure, 2011, 19: 1664-1671

3 Bledzka K, Bialkowska K, Nie H, Qin J, Byzova T, Wu C, Plow EF, Ma YQ. Tyrosine phosphorylation of integrin beta3 regulates kindlin-2 binding and integrin activation. J Biol Chem, 2010, 285: 30370-30374

4 Xu Z, Gao J, Hong J, Ma YQ. Integrity of kindlin-2 FERM subdomains is required for supporting integrin activation. Biochem Biophys Res Commun, 2013, 434: 382-387

5 Zhan J, Zhu X, Guo Y, Wang Y, Wang Y, Qiang G, Niu M, Hu J, Du J, Li Z, Cui J, Ma B, Fang W, Zhang H. Opposite role of Kindlin-1 and Kindlin-2 in lung cancers. PLoS ONE, 2012, 7: e50313

6 Yu Y, Wu J, Guan L, Qi L, Tang Y, Ma B, Zhan J, Wang Y, Fang W, Zhang H. Kindlin 2 promotes breast cancer invasion via epigenetic silencing of the microRNA200 gene family. Int J Cancer, 2013, 133: 1368-1379

7 Talaat S, Somji S, Toni C, Garrett SH, Zhou XD, Sens MA, Sens DA. Kindlin-2 expression in arsenite- and cadmium-transformed bladder cancer cell lines and in archival specimens of human bladder cancer. Urology, 2011, 77: 1507.e1-7

8 Shen Z, Ye Y, Kauttu T, Seppänen H, Vainionpää S, Wang S, Mustonen H, Puolakkainen P. Novel focal adhesion protein kindlin-2 promotes the invasion of gastric cancer cells through phosphorylation of integrin beta1 and beta3. J Surg Oncol, 2013, 108: 106-112

9 Shen Z, Ye Y, Dong L, Vainionpää S, Mustonen H, Puolakkainen P, Wang S. Kindlin-2: a novel adhesion protein related to tumor invasion, lymph node metastasis, and patient outcome in gastric cancer. Am J Surg, 2012, 203: 222-229

10 Mahawithitwong P, Ohuchida K, Ikenaga N, Fujita H, Zhao M, Kozono S, Shindo K, Ohtsuka T, Mizumoto K, Tanaka M. Kindlin-2 expression in peritumoral stroma is associated with poor prognosis in pancreatic ductal adenocarcinoma. Pancreas, 2013, 42: 663-669

11 Yu Y, Wu J, Wang Y, Zhao T, Ma B, Liu Y, Fang W, Zhu WG, Zhang $\mathrm{H}$. Kindlin 2 forms a transcriptional complex with beta-catenin and TCF4 to enhance Wnt signalling. EMBO Rep, 2012, 13: 750-758

12 Zhang HF, Zhang K, Liao LD, Li LY, Du ZP, Wu BL, Wu JY, Xu XE, Zeng FM, Chen B, Cao HH, Zhu MX, Dai LH, Long L, Wu ZY, Lai R, Xu LY, Li EM. MiR-200b suppresses invasiveness and modulates the cytoskeletal and adhesive machinery in esophageal squamous cell carcinoma cells via targeting Kindlin-2. Carcinogenesis, 2014, 35: 292-301

13 Pluskota E, Dowling JJ, Gordon N, Golden JA, Szpak D, West XZ, Nestor C, Ma YQ, Bialkowska K, Byzova T, Plow EF. The integrin coactivator kindlin-2 plays a critical role in angiogenesis in mice and zebrafish. Blood, 2011, 117: 4978-4987

14 Ussar S, Wang HV, Linder S, Fässler R, Moser M. The kindlins: subcellular localization and expression during murine development. Exp Cell Res, 2006, 312: 3142-3151

15 Etheridge T, Oczypok EA, Lehmann S, Fields BD, Shephard F, Jacobson LA, Szewczyk NJ. Calpains mediate integrin attachment complex maintenance of adult muscle in Caenorhabditis elegans. PLoS Genet, 2012, 8: e1002471

16 Dowling JJ, Vreede AP, Kim S, Golden J, Feldman EL. Kindlin-2 is required for myocyte elongation and is essential for myogenesis. BMC Cell Biol, 2008, 9: 36

17 Dowling JJ, Gibbs E, Russell M, Goldman D, Minarcik J, Golden JA, Feldman EL. Kindlin-2 is an essential component of intercalated discs and is required for vertebrate cardiac structure and function. Circ Res, 2008, 102: 423-431

18 Brunner M, Millon-Fremillon A, Chevalier G, Nakchbandi IA, Mosher D, Block MR, Albigès-Rizo C, Bouvard D. Osteoblast mineralization requires beta1 integrin/ICAP-1-dependent fibronectin deposition. J Cell Biol, 2011, 194: 307-322

19 He Y, Esser P, Schacht V, Bruckner-Tuderman L, Has C. Role of kindlin-2 in fibroblast functions: implications for wound healing. $\mathrm{J}$ Invest Dermatol, 2011, 131: 245-256

20 Hirschberg R. Kindlin-2: a new player in renal fibrogenesis. J Am Soc Nephrol, 2013, 24: 1339-1340

21 Wei X, Wang X, Xia Y, Tang Y, Li F, Fang W, Zhang H. Kindlin-2 regulates renal tubular cell plasticity by activation of Ras and its downstream signaling. Am J Physiol Renal Physiol, 2014, 306: F271-278

22 Wei X, Xia Y, Li F, Tang Y, Nie J, Liu Y, Zhou Z, Zhang H, Hou FF. Kindlin-2 mediates activation of TGF-beta/Smad signaling and renal fibrosis. J Am Soc Nephrol, 2013, 24: 1387-1398

23 Minot CS. Origin of the mesoderm. Science, 1883, 2: 815-818

24 Technau U, Scholz CB. Origin and evolution of endoderm and mesoderm. Int J Dev Biol, 2003, 47: 531-539

25 Li Y, Wang XY, Wang LJ, Xu T, Lu XY, Cai DQ, Geng JG, Yang XS. PTEN impedes EMT during chick embryo gastrulation (in Chinese). Yi Chuan, 2011, 33: 613-619

26 Kerosuo L, Bronner-Fraser M. What is bad in cancer is good in the embryo: importance of EMT in neural crest development. Semin Cell Dev Biol, 2012, 23: 320-332

27 Muller F, O'Rahilly R. The development of the human brain, the closure of the caudal neuropore, and the beginning of secondary neurulation at stage 12. Anat Embryol, 1987, 176: 413-430

28 Shi X, Wu C. A suppressive role of mitogen inducible gene-2 in mesenchymal cancer cell invasion. Mol Cancer Res, 2008, 6: 715-724

29 Hay ED. An overview of epithelio-mesenchymal transformation. Acta Anat (Basel), 1995, 154: 8-20

Open Access This article is distributed under the terms of the Creative Commons Attribution License which permits any use, distribution, and reproduction in any medium, provided the original author(s) and source are credited. 